\title{
Draagt de huisartsopleiding voldoende bij aan de klinische competentie van aankomende huisartsen?*
}

\author{
A.W.M. Kramer
}

\section{Samenvatting}

Dit artikel gaat nader in op een landelijk onderzoek naar de verwerving van klinische competentie tijdens de huisartsopleiding. Het onderzoek vond plaats van 1995 tot 1999 en betrof de twee- en driejarige opleiding. Beide opleidingen bestonden uit drie blokken van gelijke duur. In het eerste en derde blok werd stage gelopen in een huisartspraktijk, terwijl het tweede blok gereserveerd was voor ziekenhuizen, verpleeghuizen en GGZ-instellingen. De opleidingen verschilden in de duur van de blokken.

De driejarige opleiding bleek voldoende bij te dragen aan de huisartsgeneeskundige kennis en klinische vaardigheden, maar onvoldoende aan de communicatievaardigheden. Het aandeel daarbij van stages in een huisartspraktijk was groter dan dat van stages buiten de huisartspraktijk. Ook werd duidelijk dat de driejarige opleiding tot een hoger niveau van klinische competentie leidde dan de tweejarige opleiding.

Het gebrek aan toename van de communicatievaardigheden wordt toegeschreven aan de invloed van de huisartsopleider als rolmodel en aan de stages buiten de huisartspraktijk. Een onduidelijke formulering van de leerdoelen en twijfels over de kwaliteit van het onderwijs en de positie ervan midden in het curriculum lijken te hebben geleid tot de lage leeropbrengst van het tweede blok.

Het artikel eindigt met een verhandeling over de voor-en nadelen van een grootschalig, landelijk evaluatieonderzoek. De conclusie is dat het een solide maar globaal beeld geeft van de opleiding en dat diepteonderzoek nodig is om antwoord te kunnen geven op vragen als: "Wat is de invloed van de huisartsopleider op communicatievaardigheden?". Omdat de opleiding inmiddels het doel en de inrichting van het onderwijs heeft veranderd, zal breed evaluatieonderzoek nodig blijven om aan te tonen dat het nieuwe curriculum haar doel bereikt. (Kramer AWM. Draagt de huisartsopleiding voldoende bij aan de klinische competentie van aankomende huisartsen? Tijdschrift voor Medisch Onderwijs 2004;23(5):231-239.)

\section{Inleiding}

In veel landen, waaronder Nederland, heeft de huisarts een centrale rol in de gezondheidszorg. Daarom zijn in de afgelopen dertig tot veertig jaar huisartsopleidingen ingesteld om huisartsen goed voor te bereiden op deze complexe functie. Opvallend daarbij is dat nogal wat variatie bestaat in de manier waarop deze oplei- dingen zijn ingericht, zelfs bij vergelijkbare taken van de huisarts en dus bij vergelijkbare doelen van de opleiding. Dit kan betekenen dat vele wegen naar Rome leiden, in de zin dat verschillende vormen van onderwijs alle resulteren in bekwame huisartsen. Of Rome inderdaad wordt bereikt is echter zelden onderwerp van onderzoek. We weten dus niet in hoeverre

\footnotetext{
* Over dit onderzoek werd eerder door Kramer gepubliceerd in het tijdschrift Huisarts en Wetenschap 2004;47:368-71 met als titel 'Leidt de huisartsopleiding, en in het bijzonder de ELWP, op tot competente huisartsen?'
} 
huisartsen worden afgeleverd die de doelen van de opleiding hebben gehaald. Terwijl deze informatie zo belangrijk is om de huisartsopleiding mede op basis van wetenschappelijke evidentie vorm te geven. Hoewel dit voor elke opleiding geldt, is het bij uitstek van toepassing op de huisartsopleiding. Deze opleiding bevindt zich immers in een maatschappelijk krachtenveld dat aan veel verandering onderhevig is en waarin velen zich met de opleiding bemoeien. ${ }^{1}$ Visie en sturing zijn dan nodig, en wetenschappelijk bewijs kan daarbij een leidraad zijn.

De huisartsopleiding in Nederland heeft de waarde hiervan ingezien en aan het einde van het vorig decennium in een grootschalig, landelijk onderzoek de bijdrage van de opleiding aan de klinische competentie van huisartsen in opleiding onderzocht (HAIO's). ${ }^{2}$ Het onderzoek richtte zich op kennis en vaardigheden en zocht antwoord op de volgende vragen:

1. Hoe is de ontwikkeling van kennis en vaardigheden tijdens de opleiding?

2. Hebben HAIO's aan het einde van hun opleiding voldoende kennis en vaardigheden?

3. Is er een verschil tussen de tweejarige en driejarige opleiding?

Alvorens ik in deze beschouwing nader in ga op dit onderzoek, volgt eerst een beschrijving van het onderwijs om de resultaten beter op hun waarde te kunnen schatten.

\section{Inrichting van het onderwijs}

De huisartsopleiding levert onderwijs in de beroepsvormende fase. Kenmerkend voor deze fase is dat ze gebaseerd is op leren in de praktijk en de meester-gezel relatie. Ten tijde van het onderzoek - de opleiding heeft intussen enige verandering ondergaan - werkten de HAIO's vier dagen per week in de praktijk onder begeleiding van een stagebegeleider. ${ }^{2-3}$ De opleiding was in drie blokken onderverdeeld; in het eerste en derde blok werd stage gelopen in een huisartspraktijk, in het tweede blok in een ziekenhuis, verpleeghuis of GGZ-instelling. Gedurende de gehele opleiding werd één dag per week onderwijs gegeven op één van de acht opleidingsinstituten. Tijdens deze dag kregen medisch inhoudelijke zaken, consultvoering, reflectie en supervisie aandacht. Dit onderwijs vond plaats in vaste groepen van zo'n 12 HAIO's onder begeleiding van een huisarts en gedragswetenschapper.

In 1988 werd de opleiding verlengd van één naar twee jaar en ingericht volgens bovenbeschreven structuur. Men verlengde de opleiding met een jaar in 1994, omdat men twee jaar te kort achtte om alle doelen te halen. De driejarige opleiding behield dezelfde doelen en structuur, maar verschilde in de duur van de blokken: een jaar in plaats van acht maanden. Voor beide opleidingen baseerde men de inhoud van het onderwijs op het basistakenpakket van de huisarts. Er waren landelijk vastgestelde leerdoelen die richting gaven aan het landelijk toetsinstrumentarium, waarvan in dit onderzoek gebruik is gemaakt. Tabel 1 geeft de inrichting van het onderwijs in schema weer.

Concluderend kan gesteld worden dat de huisartsopleiding een gestructureerde leeromgeving bood waar HAIO's al werkend leerden onder begeleiding van een ervaren arts. Volgens de huidige inzichten is dit een krachtige leeromgeving. ${ }^{4}$

Tot slot nog een opmerking over de organisatie van de opleiding. Deze wordt verzorgd door acht opleidingsinstituten, die verbonden zijn aan de acht universitaire medische centra. Hoewel richtlijnen over de structuur en het doel van de opleiding landelijk zijn vastgesteld, hebben de instituten enige vrijheid om deze richtlijnen naar eigen inzicht vorm te geven. 
Tabel 1. De huisartsopleiding ten tijde van het onderzoek (1992-1998).

\begin{tabular}{|c|c|c|c|c|}
\hline Inhoud & Basista & ppakket van de huisarts & & \\
\hline \multirow[t]{4}{*}{ Structuur } & \multicolumn{2}{|c|}{ Drie blokken van gelijke duur } & \multicolumn{2}{|c|}{ Gedurende het curriculum } \\
\hline & Blok 1 & Stage in een huisartspraktijk & Eén dag per week: & Halve dag per week: \\
\hline & Blok 2 & $\begin{array}{l}\text { Stage in ziekenhuizen, } \\
\text { verpleeghuizen en } \\
\text { GGZ-instellingen }\end{array}$ & $\begin{array}{l}\text { theoretisch en prak- } \\
\text { tisch groepsonderwijs } \\
\text { op het opleidings- }\end{array}$ & zelfstudie \\
\hline & Blok 3 & Stage in een huisartspraktijk & instituut & \\
\hline \multirow[t]{3}{*}{ Leerdoelen } & Blok 1 & \multicolumn{3}{|c|}{$\begin{array}{l}\text { Verwerving van kennis, vaardigheden en attitudes met de nadruk op gewone } \\
\text { klachten en problemen }\end{array}$} \\
\hline & Blok 2 & \multicolumn{3}{|c|}{$\begin{array}{l}\text { Verwerving van additionele kennis, vaardigheden en attitudes die niet in de huis- } \\
\text { artspraktijk geleerd kunnen worden }\end{array}$} \\
\hline & Blok 3 & \multicolumn{3}{|c|}{$\begin{array}{l}\text { Integratie van de nieuwe kennis, vaardigheden en attitudes met de nadruk op het } \\
\text { beleid bij complexe ziektes en problemen }\end{array}$} \\
\hline
\end{tabular}

\section{Opzet van het onderzoek}

De drie onderzoeksvragen zijn in vier deelonderzoeken behandeld. Het eerste deelonderzoek betrof een vergelijking tussen de twee- en driejarige opleiding en richtte zich op alle drie de onderzoeksvragen. ${ }^{5} \mathrm{We}$ onderzochten in hoeverre de driejarige opleiding tot een hoger kennisniveau leidde en hoe de verwerving van kennis zich tijdens beide opleidingen ontwikkelde. Er is gebruik gemaakt van kennistoetsen die volgens het principe van voortgangstoetsing zijn samengesteld en waarin algemene huisartsgeneeskundige kennis wordt getoetst. Voor het onderzoek zijn de resultaten op deze toetsen gebruikt van alle HAIO's die van 1992 tot en met 1996 de tweejarige opleiding volgden, en van alle HAIO's die van 1994 tot en met 1999 de driejarige opleiding volgden (mixed longitudinal design, $\mathrm{N}=$ resp. 1563 en 2119).

De overige drie deelonderzoeken vonden in de driejarige opleiding plaats en richtten zich op de eerste twee onderzoeksvragen. We onderzochten de verwerving van klinische en communicatievaardigheden en de ontwikkeling van het eigen gevoel van klinische competentie.
Een landelijk cohort van HAIO's die van 1995-1998 de opleiding volgden, diende als onderzoekspopulatie ( $\mathrm{N}=191)$.

Voor klinische vaardigheden - vaardigheden die betrekking hebben op anamnese, lichamelijk onderzoek, diagnostiek en beleid - is de toename tijdens de opleiding nagegaan met behulp van een voortgangstoets over kennis van vaardigheden (KOV-toets), afgenomen bij alle HAIO's die op dat moment de opleiding volgden (cross-sectional design, $\mathrm{N}=775$ ). Het vaardighedenniveau aan het einde van de opleiding is bepaald met behulp van de KOV-toets, afgenomen onder HAIO's van het onderzoekscohort $(\mathrm{N}=130)$ en een stationstoets, afgenomen onder een steekproef van HAIO's van het onderzoekscohort $(\mathrm{N}=73)$. Beide toetsen zijn ook afgenomen bij huisartsopleiders ( $\mathrm{N}=$ resp. 78 en 35); zij dienden als referentiegroep. Om een uitspraak te doen over het eindniveau is gebruik gemaakt van normstellingmethoden. ${ }^{6-7}$

De toename van communicatievaardigheden hebben we onderzocht door de consulten van een steekproef van de HAIO's uit het onderzoekscohort aan het 
begin en het einde van de opleiding te vergelijken (longitudinal design, $\mathrm{N}=25$ ). ${ }^{8}$ HAIO's hadden daarvoor consulten uit de dagelijkse praktijk op video gezet. We hebben deze consulten aan het einde van de opleiding beoordeeld met behulp van een consult onafhankelijk meetinstrument, de MAAS-Globaal. Dit instrument heeft een intrinsieke normstelling. Daarnaast zijn de resultaten vergeleken met de bevindingen van een ander onderzoek, waarin de communicatievaardigheden van praktiserende huisartsen op vergelijkbare wijze zijn getoetst $(\mathrm{N}=94)$.

Tenslotte hebben de HAIO's van het onderzoekscohort aan het begin en einde van de opleiding een inschatting gegeven van hun kennis en hun klinische en communicatievaardigheden met behulp van een zelfevaluatie vragenlijst (longitudinal design, $\mathrm{N}=127$ ). Deze vragenlijst heeft een intrinsieke normstelling.

\section{Wat leerden de HAIO's}

Zowel in de tweejarige als de driejarige opleiding nam de algemene huisartsgeneeskundige kennis van de HAIO's flink toe. Beide opleidingen vertoonden een zelfde 'groeicurve': de meeste groei in de eerste acht maanden en tegen het einde van de opleiding, en stagnatie van de groei aan het einde van het tweede en het begin van het derde blok. De periode van stagnatie was in de driejarige opleiding langer, maar uiteindelijk hadden de HAIO's (gemiddeld) meer kennis aan het einde van hun opleiding dan in de tweejarige opleiding. ${ }^{5}$ Omdat kennis ten grondslag ligt aan klinische competentie en voorspellend is voor hoe een arts in de praktijk handelt, 5 wijst deze bevinding erop dat de driejarige opleiding tot een hoger competentieniveau leidde dan de tweejarige opleiding.

Voor klinische vaardigheden vonden we vergelijkbare resultaten: de toename van deze vaardigheden was even groot als die van huisartsgeneeskundige kennis en de HAIO's leerden ze het meest in het eerste half jaar van de opleiding en het minst aan het einde van het tweede blok. Aan het einde van de opleiding was het niveau voor bijna alle HAIO's (90\%) voldoende. Opvallend was wel dat de HAIO's beter presteerden op de zogenaamde integrale vaardigheden - vaardigheden die nodig zijn in een geheel consult en zowel anamnese, lichamelijk onderzoek als beleid omvatten - dan op geïsoleerde, meer technische vaardigheden, zoals het inbrengen van een spiraaltje. In vergelijking met de huisartsopleiders waren de HAIO's even goed in integrale vaardigheden en beter in technische vaardigheden. ${ }^{6}$

Bij communicatievaardigheden vonden we een totaal verschillend patroon: er trad bijna geen toename op en aan het einde van de opleiding was het (gemiddelde) niveau onvoldoende. De HAIO's waren wel even goed (of slecht) in communicatievaardigheden als ervaren huisartsen. ${ }^{8}$

Tot slot het eigen gevoel van competentie. De HAIO's vonden dat ze aan het begin van de opleiding enige kennis, klinische en communicatievaardigheden hadden; aan het einde was dat beduidend meer, ze schatten hun niveau voor alle drie de aspecten redelijk tot goed in.

Uit deze resultaten trek ik de volgende conclusies:

- De toenmalige driejarige huisartsopleiding droeg voldoende bij aan de verwerving van kennis, klinische vaardigheden en de mate waarin HAIO's zichzelf competent achtten, en lijkt onvoldoende te hebben bijgedragen aan communicatievaardigheden.

- De driejarige opleiding leidde tot een hoger niveau van klinische competentie dan de tweejarige opleiding.

- De stages buiten de huisartspraktijk hebben minder bijgedragen aan de ver- 
werving van huisartsgeneeskundige kennis en klinische vaardigheden dan de stages in een huisartspraktijk.

- De HAIO's die de toenmalige driejarige opleiding bijna voltooid hadden, presteerden beter op het gebied van klinische vaardigheden dan ervaren huisartsen en vergelijkbaar wat betreft communicatievaardigheden.

\section{Discussie}

\section{Lessen voor de opleiding}

Uitgangspunt was een krachtige leeromgeving waarvan verwacht kan worden dat deze goede resultaten boekt. Deze verwachting is uitgekomen voor huisartsgeneeskundige kennis en klinische vaardigheden en voor het eigen gevoel van competentie. Voor communicatievaardigheden zijn de bevindingen minder eenduidig. Mogelijk leren de HAIO's deze onvoldoende, ondanks de grote aandacht die deze vaardigheden krijgen in het onderwijs. Er zijn echter ook vraagtekens te zetten bij het gebruikte onderzoeksinstrument en de onderzoeksopzet. ${ }^{8}$ Daarnaast roept de bijdrage van de huisartsopleider en de stages buiten de huisartspraktijk aan de klinische competentie vragen op.

De huisartsopleiding kan tevreden zijn met dit resultaat; het toont aan dat het op een groot aantal punten goed gaat en het geeft aanwijzingen voor verbetering. Voor dit laatste is het nodig inzicht te hebben in de reden waarom zaken niet goed lopen. Hoewel het onderzoek zich vooral gericht heeft op het resultaat van de opleiding, biedt het hiervoor enige aanknopingspunten.

Ten eerste communicatievaardigheden. Een verklaring voor het uitblijven van een toename van deze vaardigheden zou kunnen zijn dat ze afnemen tijdens de stages buiten de huisartspraktijk. De aandacht voor en de eisen die gesteld worden aan het patiëntencontact zijn immers anders in een ziekenhuis, verpleeghuis of GGZinstelling dan in de huisartspraktijk. Een andere verklaring is de invloed van de huisartsopleider. Als meester levert deze een belangrijke bijdrage in het onderwijs, niet in de laatste plaats als rolmodel. Juist bij het aanleren van communicatievaardigheden, waar het niet alleen gaat om gesprekstechniek maar ook om attitude, is de invloed van het rolmodel groot. Het is goed denkbaar dat de bijdrage van de huisartsopleider in deze minder optimaal is geweest, gezien het lage communicatieniveau van ervaren huisartsen.

Ten tweede de stages buiten de huisartspraktijk. Hier is enige toelichting op zijn plaats. Bij de invoering van deze stages, in 1988, is het doel ruim gedefinieerd: het leren van die kennis, vaardigheden en attitudes die nodig zijn om een bekwame huisarts te worden, maar die men niet in de huisartspraktijk en tijdens het instituutsonderwijs kan leren. De stageperiode werd bewust midden in het curriculum geplaatst. Men ging er van uit dat de HAIO in het eerste blok voldoende vertrouwd raakte met de huisartsgeneeskunde om vanuit het perspectief van aankomend huisarts gebruik te kunnen maken van de leeromgeving buiten de huisartspraktijk. In het laatste blok, tenslotte, zou de HAIO dan de nieuwe kennis en vaardigheden kunnen integreren in het werk als huisarts. Uit de resultaten van het onderzoek blijkt nu dat de toename van huisartsgeneeskundige kennis en klinische vaardigheden stagneert in deze periode. Er zijn ook geen aanwijzingen voor een bijdrage aan communicatievaardigheden. Maar wat leren HAIO's er dan wel en past dit binnen de doelstelling van de opleiding? Omdat het doel zo ruim is gedefinieerd, is deze vraag lastig te beantwoorden. Huisartsgeneeskunde is een breed, generalistisch specialisme, waardoor het 
veel raakvlakken heeft met andere (para-) medische disciplines. Dat maakt dat allerlei ervaringen, wetenswaardigheden en vaardigheden al snel interessant en relevant zijn, maar of ze echt nodig zijn om een bekwame huisarts te zijn is nog maar de vraag. De huisartsopleiding zou er daarom goed aan doen eerst te omschrijven welke noodzakelijke kennis, vaardigheden en attitudes níet in de huisartspraktijk en op het instituut geleerd kunnen worden, om vervolgens te kunnen bepalen in welke leeromgeving en wanneer in het curriculum deze het beste geleerd kunnen worden. Daarbij zou men rekening moeten houden met de gevolgen van dit onderwijs voor de andere leerdoelen van de opleiding. De mogelijk negatieve invloed van de stages buiten de huisartspraktijk op communicatievaardigheden zijn immers een mooi voorbeeld van hoe leerdoelen met elkaar kunnen interfereren. Ook verschillen in competentie tussen HAIO's bij aanvang van de opleiding zou men in ogenschouw moeten nemen. HAIO's kunnen immers door hun werken/of leerervaringen voorafgaand aan de huisartsopleiding al de additionele kennis en vaardigheden hebben opgedaan die ze nodig hebben als huisarts maar die ze niet in de huisartspraktijk kunnen leren.

Een andere verklaring biedt de kwaliteit van het onderwijs. Uit de literatuur weten we dat het onderwijs tijdens co-assistentschappen in ziekenhuizen niet optimaal is. ${ }^{9}$ Dit gold zeer waarschijnlijk ook voor de ziekenhuisstages in de huisartsopleiding, waarvan we weten dat er minder aandacht was voor onderwijs dan in de huisartspraktijk en, hoewel in mindere mate, voor de stages in verpleeghuizen en GGZ-instellingen. ${ }^{3} \mathrm{Er}$ is dus een grote kans dat de kwaliteit van het onderwijs tijdens deze stages minder goed is geweest dan die van de stages in de huisartspraktijk. Dit kan ook hebben bijgedragen aan het verschil in leeropbrengst tussen beide stageperiodes.

Overigens heeft de huisartsopleiding in de afgelopen jaren de stages buiten de huisartspraktijk al enigszins aangepast. ${ }^{10}$ Er zijn specifiekere doelen geformuleerd, er wordt rekening gehouden met extra expertise bij aanvang van de opleiding en er is meer aandacht voor het onderwijsproces. Echter, een principiële discussie over nut en inrichting van dit stageonderwijs ontbreekt. Men zou zich daarbij moeten afvragen of aparte, grote stages buiten de huisartspraktijk wel nodig zijn; of een deel van de doelen van deze periode niet al behaald is tijdens de basisopleiding; of het laatste jaar daarvan, het zogenaamde schakeljaar, daarin een rol zou kunnen spelen; en, tenslotte, of andere leeromgevingen niet meer geschikt zijn of een combinatie van leeromgevingen, zoals bijvoorbeeld per week drie dagen huisartspraktijk en één dag poli kleine verrichtingen.

Tot slot een opmerking over zelfevaluatie. Uit het onderzoek blijkt dat HAIO's vinden dat hun communicatievaardigheden het meest zijn toegenomen, terwijl dit objectief gemeten niet het geval is. Kennelijk dragen andere factoren dan 'echte' competentie bij aan het gevoel competent te zijn. De vraag is welke factoren dat zijn. En de tweede vraag die het oproept is wat we eigenlijk meten met zelfevaluatie. Hoewel de literatuur allerlei suggesties doet, zoals dat het zou verwijzen naar zelfvertrouwen of naar niet-cognitieve competentie, ontbreekt een theoretisch concept over zelfevaluatie in het medisch onderwijs. Terwijl het wel op grote schaal wordt toegepast, zowel in het medisch onderwijs als daarna tijdens de zelfstandige beroepsuitoefening waar artsen zelf verantwoordelijk zijn voor hun leerproces. De nadruk op zelfevaluatie wordt zelfs groter nu er in het onderwijs steeds meer 
wordt uitgegaan van zelf gestuurd leren. ${ }^{10}$ Kennelijk is zelfevaluatie een belangrijke drijfveer voor leren maar het blijft onduidelijk wat de invloed ervan is op de ontwikkeling van klinische competentie.

\section{Lessen voor evaluatieonderzoek}

Behalve lessen over de opleiding leert het onderzoek ons ook over evaluatieonderzoek. Het betreft in dit geval een breed, grootschalig en landelijk onderzoek naar de effecten van een opleiding. De ervaringen die hiermee zijn opgedaan laten zien dat een dergelijke benadering voor- en nadelen heeft. Ik zal deze achtereenvolgens bespreken na een korte uiteenzetting over de uitvoering van het onderzoek.

Het onderzoek is uitgevoerd door het landelijk bureau Toetsing, Evaluatie en Onderzoek van onderwijs (bureau TEO), in opdracht van de hoofden van de acht opleidingsinstituten. Dit bureau is een gemeenschappelijke activiteit van de acht instituten. Het is niet direct betrokken bij de uitvoering van het onderwijs en heeft enige mate van zelfstandigheid. Het is verankerd in de opleiding door middel van werkgroepen waarin vertegenwoordigers van de instituten en het bureau samenwerken. Ook voor het hier beschreven onderzoek bestond er zo'n werkgroep.

\section{Voordelen}

Alle instituten hebben aan het onderzoek meegedaan en de medewerking van de stafleden was goed. Hiertoe heeft zeker bijgedragen dat bureau TEO de steun had van de beleidsmakers: de hoofden waren immers opdrachtgever. Ook de betrokkenheid van het bureau bij de opleiding - dit in tegenstelling tot een geheel onafhankelijk onderzoeksbureau - heeft een positieve invloed gehad. Gevolg was dat veel HAIO's aan het onderzoek hebben deelgenomen.

Omdat het onderzoek is uitgevoerd door een landelijk bureau dat toegespitst is op toetsing en evaluatie, was enige mate van objectiviteit en kwaliteit gegarandeerd. Objectiviteit omdat het bureau niet direct bij de opleiding was betrokken. Kwaliteit omdat voldoende onderwijskundige en huisartsgeneeskundige deskundigheid in huis was. Het bureau had daarnaast de beschikking over door haar ontwikkelde en geïmplementeerde toetsinstrumenten. Dit had als voordeel dat instrumenten zijn ingezet waarvan de validiteit, betrouwbaarheid en toepasbaarheid bekend waren. Tevens waren bij het bureau de voorzieningen aanwezig voor de verwerking van grote hoeveelheden toetsgegevens.

\section{Nadelen}

Landelijke aansturing verkleint de betrokkenheid van degenen die het onderzoek lokaal moeten uitvoeren. Het onderzoek kan daardoor worden ervaren als 'van boven af opgelegd' en dat kan weerstand oproepen, temeer daar evaluatieonderzoek toch al vaak als bedreigend wordt ervaren. Als het onderzoek dan ook nog drie jaar duurt, waardoor de resultaten pas laat bekend zijn, kan dit leiden tot een bemoeilijkte acceptatie en waardering van het onderzoek en haar resultaten. Er zijn aanwijzingen dat dit in het hier beschreven onderzoek ook het geval is geweest.

Landelijke aansturing had ook nadelen voor de uitvoering van het onderzoek. Er was minder zicht op lokale omstandigheden, zodat goede logistiek lastiger was. Ook was er minder invloed op de uitvoering, zodat minder bijgestuurd kon worden als zaken niet goed gaan.

Een ander nadeel was de beperking in de keuze van toetsinstrumenten. Alleen die instrumenten kwamen in aanmerking die relatief eenvoudig zijn toe te passen, zoals bijvoorbeeld kennistoetsen of vragenlijsten. Wanneer wel gebruik werd ge- 
maakt van ingewikkelde toetsmethodes, was de beperking het aantal HAIO's dat getoetst kon worden. Tot slot, in het onderzoek is uitgegaan van acht instituten die één opleiding verzorgen. Hoewel dit op papier zo is, bestaan er in de praktijk verschillen tussen hoe de instituten het onderwijs vorm geven. Inzicht in het onderwijsproces is nodig om een koppeling te kunnen maken tussen proces en resultaat. Een landelijk onderzoek bemoeilijkt een dergelijke koppeling.

\section{Conclusie}

Het onderzoek heeft belangrijke inzichten gegeven over de effecten van de huisartsopleiding. De kracht van het onderzoek is dat het een solide maar globaal beeld geeft van die opleiding; we weten waar het in grote lijnen goed gaat en waar niet. Hiermee kan de huisartsopleiding verantwoording afleggen aan de buitenwereld en het onderwijs verbeteren. De bevindingen vragen tevens om onderzoek dat meer de diepte in gaat, om antwoord te kunnen geven op vragen als: "Wat is de invloed van de huisartsopleider op communicatievaardigheden?", "Wat wordt er tijdens stages buiten de huisartspraktijk geleerd en is dat voldoende relevant voor de aankomende huisarts?" of "Welke factoren dragen bij aan het eigen gevoel van competentie?". Omdat de opleiding inmiddels het doel en de inrichting van het onderwijs heeft veranderd, ${ }^{10-11}$ zal breed evaluatieonderzoek nodig blijven om aan te tonen dat het nieuwe curriculum haar doel bereikt.

\section{Literatuur}

1. De wereld verandert en de huisarts verandert mee. Utrecht: LHV; 1995.

2. Kramer A. Acquisition of clinical competence during postgraduate training in general practice [dissertatie]. Maastricht: Datawyse/Universitaire Pers Maastricht; 2003. Een Nederlandse samen- vatting is te vinden op www.svuh.nl (onder 'onderzoek van onderwijs').

3. Tan LHC, Kramer AWM. Opleiding doorgelicht. Utrecht: SVUH; 1999.

4. Vleuten $C$ van der, Scherpbier A. De rol van de onderwijskundige in de beroepsopleiding. In: Kramer A, Jansen J, editors. Waardering van onderwijs. Utrecht: SVUH; 2000.

5. Kramer AWM, Düsman H, Tan LHC, Jansen JJM, Grol RPTM, Vleuten CPM van der. Effect of extension postgraduate training in general practice on the acquisition of knowledge of trainees. Fam Prac 2003;20:207-12.

6. Kramer AWM, Jansen JJM, Düsman H, Tan LHC, Vleuten CPM van der, Grol RPTM. Acquisition of clinical skills in postgraduate training for general practice. Br J Gen Prac 2003;53:677-82.

7. Kramer AWM, Muijtjens AMM, Jansen JJM, Düsman H, Tan LHC, Vleuten CPM van der. Comparison of a rational and an empirical standard setting procedure for an OSCE. Med Educ 2003;37:132-9.

8. Kramer AWM, Düsman H, Tan LHC, Jansen JJM, Grol RPTM, Vleuten CPM van der. Acquisition of communication skills in postgraduate training for general practice. Med Educ 2004;38:158-67.

9. Wolfhagen HAP, Gijselaers WH, Dolmans D, Essed G, Schmidt HG. Improving clinical education through evaluation. Med Teach 1997;19:99103.

10. Onstenk JHAM, Swager R. Raamplan Huisartsopleiding. 's Hertogenbosch: Cinop; 2001.

11. Berkestijn LGM van. Ontwikkelingen in de huisartsopleiding. Huisarts Wet 2003;46:672-5.

De auteur:

Mw. dr. A.W.M. Kramer, huisarts, is verbonden aan de Voortgezette Opleiding tot Huisarts (VOHA) van het UMC St Radboud te Nijmegen.

Correspondentieadres:

Mw. dr. A.W.M. Kramer, Mauritsstraat 92, 3583HV

Utrecht, tel: 030-2518032, carol_ann@tiro.nl. 


\section{Summary}

This paper discusses a national evaluation study into the acquisition of clinical competency during Dutch postgraduate training in general practice. The study took place from 1995 to 1999 and included the two-year and three-year training programme. Both programmes were composed of three blocks of equal length. The first and third blocks were reserved for practical training in a general practice whereas the second block was dedicated to rotations through hospitals, clinics for chronically ill patients and psychiatric outpatients clinics. The curricula differed in the duration of the blocks.

The main findings were that the three-year training contributed satisfactory to the acquisition of knowledge and clinical skills but did not seem to improve communication skills; that the contribution of practical training in a general practice (first and third block) was greater than that of practical training outside general practice (second block); and that the three-year programme leaded to a higher level of clinical competence than the two-year programme.

The lack of increase of communication skills is attributed to the influence of the GP-trainer as a role model and to the practical training outside general practice. Vague learning objectives and doubts about the quality of the education and the position in the middle of the curriculum are accounted for the disappointing results of the second block.

The paper ends with a discussion about the advantages and disadvantages of a comprehensive national evaluation study. The conclusion is that it gives a solid but global impression of Dutch postgraduate training and that in-to-depth research is necessary to answer questions as: "What is the influence of the GP-trainer on the acquisition of communication skills?" As Dutch postgraduate training has recently changed aim and structure of the programme, comprehensive evaluation will be necessary to show that the new curriculum achieves its objectives. (Kramer AWM. Does postgraduate training in general practice contribute satisfactory to the acquisition of clinical competency? Dutch Journal of Medical Education 2004;23(5):231-239.) 